\title{
MENELAAH WAKAF PRODUKTIF ATAS SOLUSI MASALAH UMAT BERDASARKAN PSAK 112
}

\author{
Ikhwatun Hasanah \\ Fakultas Agama Islam, Universitas Muhammadiyah Banjarmasin \\ Email : ikhwatunhasanah@ymail.com
}

\begin{abstract}
ABSTRAK
Ketika sebuah standar lahir karena banyaknya keingintahuan masyarakat tentang sebuah aturan yang dapat dijadikan sebuah pedoman bagi pengelolaan sebuah entitas, maka tantangannya bagaimana mengenalkan standar tersebut menjadi aturan yang diterima umum. Menjawab fenomena tersebut, maka Ikatan Akuntan Indonesia (IAI) mengeluarkan sebuah standar yang khusus mengatur tentang wakaf. Disahkannya PSAK 112 tentang Akuntansi Wakaf berlaku efektif 01 Januari 2021 dengan opsi dapat berlaku dini, menandai tata kelola perwakafan yang akuntabel, dan transparan. Adanya standar ini membuat beberapa lembaga pengelola perhimpunan wakaf yang saat ini melakukan pemberdayaan wakaf (baik wakaf yang selama ini dikenal masyarakat luas, maupun wakaf produktif) bergegas membenahi pengelolaan pelaporannya. Pengimplementasian PSAK 112 ini bagi para nazhir dan wakif mewakili lembaga perwakafan guna menyeragamkan bentuk laporan keuangannya.
\end{abstract}

Kata kunci : Wakaf, Wakaf Produktif, Nazhir, Wakif, Penerapan PSAK 112

\begin{abstract}
When a standard is present because a public interest about a rule that can be used as a guideline for managing an entity, then the challenge is how to introduce these standards to become generally accepted rules. Responding to the phenomenon, the Indonesia Institutue of Accountants (IAI) issued a standard that specifically regulates chaitantable (waqf). The ratification Principles statement of Financial Accounting standards 112 (PSAK 112) concerning accounting for chaintantable (waqf) will be effective on Januari $1^{\text {st }}, 2021$ with an option to take effect early, marking the accountable and tranparent management of waqf. The existence of this standard has made several chaitantable-waqf emprowerment (both waqf which has been known to the wider community, as well as productive waqf). Haste to fix their reporting management. The implementation of PSAK 112 for a waqf implementer (nazhir) and waqif representing representantive institutions in order to synonyms of financial statement
\end{abstract}

Keywords : Chaintantable Waqf, Productive of Waqf, Waqf Implementer (Nazhir), Waqif, Implementation Principles of Accounting Standards 112 (PSAK 112). 


\section{PENDAHULUAN}

Saat ini pemberdayaan harta wakaf menjadi wakaf produktif merupakan salah satu solusi dari permasalahan umat (ummat). Harta wakaf semisal wakaf tanah dimanfaatkan menjadi lahan pertanian, pengairan, perikanan-budidaya ikan air tawar (tambak, empang) hingga dijadikan lahan perkebunan yang ditanami sayuran organik, sayuran hydroponic atau sejenisnya, pesantren serta minimarket dan lain sebagainya. Pendapatan dari pemanfaatan tanah wakaf tersebut digunakan untuk mensejahterahkan umat dimana proses dan hasil produksi akan kembali kemasyarakat tersebut yang secara otomatis bertujuan agar masyarakat mampu hidup secara mandiri.

Selanjutnya hasil dari pengelolaan harta wakaf yang produktif tidak hanya memenuhi kebutuhan pangan masyarakat sekitar, namun mampu memandirikan para penerima hasil dan manfaat yang biasa disebut mauquf'alaih. Mandiri disini diartikan mandiri secara ekonomi, pendidikan maupun kesehatan, sehingga tidak terdapat lagi masyarakat yang terpuruk untuk memenuhi kebutuhan 3 (tiga) aspek tersebut.

Pengelolaan harta wakaf yang bertujuan memberdayakan masyarakat agar menjadi masyarakat mandiri haruslah dilakukan dengan upaya terus menerus, memaksimalkan segala kemampuan yang dimiliki. Praktik pemberdayaan ini dalam upaya pengaplikasian atas mensyukuri karunia-Nya dan menjalankan perintahNya mengikuti jejak Rasulullah SAW beserta para sahabat yang sudah berhasil dalam pengelolaan harta wakaf.

Hal yang harus digaris bawahi disini yaitu tentang "ilmu pemberdayaan" yang dimiliki oleh setiap pelaku serta pengelola harta wakaf sebagai stakeholder pada permasalahan ini. Adanya ilmu dan pemahaman menjadi indikator penentu agar mendapatkan solusi dan menyelesaikan problem yang dihadapi. Ketika seorang Nazhir (pengelola harta wakaf) memahami ilmu pemberdayaan dan kemandirian ekonomi umat, sehingga harta wakaf yang dikelola menghasilkan sesuatu yang bermanfaat.

Selain pengelolaan pemberdayaan wakaf menjadi produktif dibutuhkan pula pengetahuan nazhir tentang pelaporan yang sesuai dengan standar yang ada, dalam hal ini mengacu pada SAK (Standar Akuntansi Keuangan) sebagai salah satu pedoman dalam pengelolaan keuangan.

Adanya tuntunan dari masyarakat agar transparansi dan pelaporan pengelolaan dana abadi wakaf produktif dikelola dengan menggunakan suatu standar baku bagi Laporan Keuangan, dimana standar pelaporan saat ini masih mengacu pada standar lama yang menggunakan PSAK 109 tentang akuntansi zakat, infak, sedakah dikarenakan belum adanya standar khusus wakaf. Berdasarkan fenomena tersebut, serta melihat telah disahkannya PSAK 112 tentang Akuntansi Wakaf, maka penulis mencoba mengungkapkan telaah literasi sebagai masukan bagi lembaga wakaf maupun bagi nazhir dan .

\section{TINJAUAN PUSTAKA}

\section{Karakteristik Wakaf}

\section{Pengertian Wakaf}

Dikalangan ulama fiqih terdapat perbedaan dalam mendefinisikan wakaf. Berikut beberapa pandangan ulama ( $\mathrm{Al}$ Qaradhawi, 1993) :

a. Menurut Ulama Hanafiah Wakaf adalah menahan benda milik orang yang berwakaf dan menyedekahkan manfaatnya untuk kebaikan, baik untuk sekarang atau masa yang akan datang.

b. Menurut Ulama Malikiyah Wakaf adalah waqif menjadikan manfaat harta yang dimilikinya walaupun 
berupa sewa ataupun hasilnya seperti dirham (uang) dengan sighat tertentu dalam jangka waktu tertentu sesuai kehendak waqif.

c. Menurut Ulama Syafi'iyah Wakaf artinya menahan harta yang dapat dimanfaatkan dengan tetapnya zat benda yang menghalangi waqif dan lainnya dari tindakan hukum yang persetujuannya untuk kebaikan dan mendekatkan diri kepada Allah SWT.

d. Menurut Ulama Hambali Wakaf tidaklah bersifat lazim kecuali waqif melepaskan hak kepemilikannya dari kekuasaannya dan menyerahkan kepada orang lain, waqif tidak dapat menarik kembali harta wakafnya.

Dalam Undang-undang No. 41 Tahun 2004 Tentang wakaf, Pasal 1 dirumuskan wakaf adalah perbuatan hukum waqif untuk memisahkan dan/atau menyerahkan sebagian harta benda miliknya untuk dimanfaatkan selamanya atau jangka waktu tertentu sesuai dengan kepentingannya guna keperluan ibadah dan/atau kesejehteraan umum menurut syari'at. Undang-undang ini menggambungkan pendapat ulama fiqih tentang wakaf.

\section{Syarat Sah Wakaf}

Beberapa ulama memiliki perbedaan pandangan tentang kriteria kesahan wakaf, namun menurut jumhur ulama, rukun wakaf ada 4 (empat), (Departemen Agama, 2011):

1. Waqif (orang yang berwakaf). Orang yang berwakaf disyaratkan cakap hukum sehingga memenuhi persyaratan:

a. Berakal. Para ulama sepakat agar waqif dipandang sah maka waqif berakal ketika melaksanakan wakaf, oleh karena itu tidak dipandang sah jika wakaf yang dilakukan oleh orang gila, idiot, pikun dan pingsan. b. Balig (Baligh). Orang yang berwakaf haruslah orang dewasa atau cukup umur (kisaran umur 9 sampai 15 tahun), sehingga tidaklah sah wakaf yang dilakukan oleh anak kecil yang belum balig karena belum mumayiz.

c. Cerdas. Orang yang berwakaf harus cerdas dan memiliki kemampuan serta kecakapan melakukan tindakan.

d. Atas Kemauan Sendiri. Wakaf dilakukan atas kemauan sendiri, bukan karena paksaan dari pihak lain. Tidak sah hukumnya apabila wakaf karena paksaan baik dari keluarga ataupun lingkungan.

e. Waqif adalah orang yang merdeka dan pemilik harta wakaf. Tidak sah wakaf yang dilakukan oleh seorang budak karena ia pada dasarnya tidak merdeka dan tidak memiliki harta. Begitu pula tidak sah mewakafkan harta orang lain atau harta yang dicuri.

2. Mauquf (Benda Yang Diwakafkan)

a. Objek wakaf atau benda wakaf adalah harta yang berwujud, bisa dinilai harganya. Seperti pekarangan, tanah, rumah sesuai ijma' ulama, atau barang yang bisa dipindahkan seperti buku, pakaian, hewan, senjata.

b. Benda wakaf diketahui dengan jelas keberadaannya, batasan dan tempatnya, seperti mewakafkan 1.000 meter tanah yang berbatasan dengan tanah Tuan A., oleh karena itu, tidak sah mewakafkan sesuatu yang tidak jelas, contohnya seseorang mewakafkan tanah saya yang berada di kota P., sementara ia tidak menjelaskan posisi yang pasti dan batasan-batasan tanah tersebut. 
3. Mauquf' Alaih (Sasaran atau Tujuan Wakaf). Secara umum wakaf ditujukan untuk mendekatkan diri pada Allah SWT. Adapun secara umum tujuan wakaf ialah:

a. Pihak yang diberi wakaf adalah pihak yang berorientasi pada kebaikan dan tidak bertujuan maksiat.

b. Sasaran diarahkan pada aktivitas kebaikan yang kontinu.

c. Peruntukkan wakaf tidak dikembalikan pada waqif.

4. Sighat Waqf (Ikrar Wakaf). Ikrar wakaf adalah pernyataan kehendak dari waqif untuk mewakafkan benda miliknya. Adapun syarat lafal wakaf adalah:

a. Pernyataan wakaf bersifat Ta'bid (untuk selama-lamanya).

b. Pernyataan wakaf bersifat Tanjiz, yaitu wakaf itu jelas menunjukkan terjadinya wakaf dan memunculkan akibat hukum wakaf.

c. Pernyataan wakaf bersifat tegas.

d. Pernyataan wakaf tidak diiringi dengan pernyataan wakaf yang batal, yakni syarat yang meniadakan makna wakaf, atau bertentangan dengan tabiat wakaf. Misalnya diungkapkan "saya wakafkan tanah ini dengan syarat tanah ini tetap milik saya", maka wafat seperti ini batal.

\section{Wakaf Produktif}

Wakaf produktif adalah sebuah skema pengelolaan donasi wakaf dari umat, yaitu memproduktifkan donasi tersbut, hingga mampu menghasilkan surplus yang berkelanjutan. Donasi wakaf berupa benda bergerak seperti uang dan logam mulia, maupun benda tidak bergerak, seperti tanah dan bangunan.
Surplus dari wakaf produksi ini kemudian menjadi sumber dana abadi untuk pembiayaan pendidikan dan pelayanan kesehatan yang berkualitas (Departemen Agama, 2006).

Proses pengolahan produktivitas tidak dibatasi dengan aturan apapun, selama halal, bisa dalam bentuk peternakan, perkebunan hingga saham.

Contoh beberapa Negara yang berhasil mengembangkan wakaf demi kesejahteraan umat, diantaranya (Rozalinda, 2015): Di Negara Bahrain, Central Bank of Bahrain mengelola dana wakaf yang diamanahkan oleh 20 Bank Syariah yang terdaftar pada CBB. Dana wakaf itu digunakan membiayai program pendidikan keuangan syariah demi kemajuan keuangan syariah negaranya.

Sedangkan di Jordania, pengelolaan wakaf diperuntukkan bagi kesejahteraan masyarakat. Pengelolaannya digunakan bagi perumahan, pertanian, bahkan pengembangan pariwisata.

Melihat hal ini, diharapkan Indonesia sebagai negara mayoritas muslim dapat mengumpulkan dana wakaf yang dapat didonasikan serta dikelola dengan baik lagi benar, serta akuntabel dan transparan. Sehingga kedepannya menjadi solusi bagi kesejahteraan umat sesuai dengan pengamalan Pancasila sila ke 5 (lima) keadilan sosial bagi seluruh rakyat Indonesia.

\section{Wakaf Uang}

Ulama Hanafiyah memperbolehkan benda bergerak asalkan hal itu sudah menjadi urf' (biasaan) dikalangan masyarakat, seperti mewakafkan buku, mushaf Alqur'an dan uang.

Dalam masalah wakaf uang ulama hanafiyah mensyaratkan harus ada istibdal (konversi) dari benda yang diwakafkan bila dikhawatirkan ada ketidaktepatan zat benda (Asnaini, 2008). 
Menghadapi era digitalisasi perubahan atas pengeloaan wakaf tunai atau uang terus digalakkan, agar semakin tinggi minat masyarakat menunaikan wakaf. Salah satu lembaga nazhir yang mengelola wakaf produktif yaitu Baitul Wakaf Hidayatullah. Bentuk pengelolaan wakaf dari BWH diantaranya wakaf minimarket SakinahMart, wakaf RS. Madani, wakaf pesantren putri, wakaf Alqur'an, wakaf sarana sekolah (Sekolah Pemimpin).

Baitul Wakaf Hidayatullah mampu berdiri sendiri dan mengembangkan berbagai usaha yang dibiayai oleh penghimpunan dana wakaf dari para waqif, donatur, sehingga beberapa masalah diantaranya ekonomi, pendidikan, kesehatan dapat diatasi dengan pemberdayaan wakaf produktif tersebut.

\section{Dasar Hukum Wakaf}

Di Indonesia terdapat peraturan yang mengatur mengenai perwakafan, diantaranya (Fryanti, 2017):

1. Undang-Undang RI No 41 Tahun 2004 Tentang wakaf.

2. Peraturan Pemerintah No.42 Tahun 2006 Tentang Pelaksanaan UU No.41/2004.

3. Peraturan-peraturan Badan Wakaf Indonesia.

4. Peraturan Menteri Agama RI No.4 tahun 2009 Tentang Administrasi Wakaf Uang.

5. Peraturan Menteri Agama RI No.73 tahun 2013 Tentang Tata cara perwakafan benda tidak bergerak dan benda bergerak selain uang.

6. Keputusan Lembaga Menteri Agama tentang Penetapan Lembaga Keuangan Syariah Penerima Wakaf Uang (LKSPWU).

\section{Badan Wakaf Indonesia (BWI)}

Berdasarkan Undang-Undang RI No 41 Tahun 2004 tentang Wakaf, Badan Wakaf Indonesia (BWI) adalah lembaga independen yang bertugas untuk mengembangkan dan memajukan perwakafan di Indonesia. BWI berdiri pada tahun 2007 setelah terbitnya Peraturan Pemerintah No. 42 Tahun 2006 tentang Pelaksanaan Undang-Undang No.41 Tahun 2004 tentang Wakaf.

Berdasarkan Undang-Undang RI No 41 Tahun 2004 BWI terdiri dari Badan Pelaksana dan Dewan Pengawas. Badan Pelaksana merupakan unsur pelaksana BWI sedangkan Dewan Pengawas adalah unsur pengawas pelaksana BWI. Masingmasing lembaga terdiri dari satu orang ketua dan dua orang wakil ketua. Keanggotaan BWI terdiri paling sedikit 20 (dua puluh) orang dan paling banyak 3 (orang) dari unsur masyarakat.

Badan Wakaf Indonesia mempunyai tugas dan wewenang, yaitu:

1) Melakukan pembinaan terhadap nazhir dalam mengelola dan mengembangkan harta benda wakaf.

2) Melakukan pengelolaan dan pengembangan harta benda wakaf berskala nasional dan internasional.

3) Memberikan persetujuan dan/atau izin atas perubahan peruntukkan dan status harta benda wakaf.

4) Memberhentikan dan mengganti Nazhir.

5) Memberikan persetujuan atas penukaran harta benda wakaf.

6) Memberikan saran dan pertimbangan kepada Pemerintah dalam penyusunan kebijakan dibidang perwakafan.

Berdasarkan hasil penelitian terdahulu pada beberapa lembaga wakaf dan/atau baitul wakaf, masih banyak yang berpedoman pada PSAK 110 tentang 
Akuntansi ZIS, dikarenakan belum mengetahui telah disahkannya PSAK 112 tentang Akuntansi wakaf. Laporan Keuangan pengelola dana wakaf masih mengikuti format pelaporan BWI (Badan wakaf Indonesia) menggunakan single entry (Nugraha, 2019). Sejalan dengan penelitian tersebut, perlakuan akuntansi wakaf pada pelaporan di BWI Kota Batam belumlah seutuhnya sesuai dengan PSAK 112, dikarenakan secara konseptual ada beberapa pengakuan serta pengukuran yang belum disesuaikan dengan standar tersebut, sehingga dapat disimpulkan bahwa penerapan PSAK 112 belum sepenuhnya diterapkan (Putri \& Santoso, 2020)

Hasil penelitian berbeda diperoleh (Maria \& Rahman, 2019), bahwa sebagian besar ketentuan dalam PSAK 112 telah diterapkan meskipun nazhir belum melakukan penyusunan laporan keuangan di Majelis Wakaf Muhammadiyah Yogyakarta. Sehingga disimpulkan bahwa pengimplementasian PSAK 112 ini membutuhkan sosialisasi menyeluruh guna menyeragamkan pelaporan keuangan lembaga pengelolaan dana wakaf.

\section{METODE PENELITIAN}

Penelitian ini menggunakan metode kualitatif dalam bentuk studi kasus (J. Moleong, 2007), karena ingin menggambarkan penerapan PSAK 112 tentang akuntansi wakaf pada lembaga pengelola wakaf dan pendekatan deskriptif dengan prosedur penggambaran objek penelitian pada saat sekarang berdasarkan fakta yang tampak atau sebagaimana adanya (Sugiono, 2013).

\section{HASIL DAN PEMBAHASAN}

\section{Laporan Keuangan Lembaga Wakaf}

Lembaga wakaf atau sering disebut Badan Wakaf ada yang berdiri sendiri sebagai Badan Wakaf, dan ada pula yang bergabung dalam Lembaga Amil Zakat tetapi miliki Nazhir wakaf.

\section{Standar Laporan Lembaga Wakaf}

Standar laporan untuk lembaga wakaf hingga tahun 2017 belum memiliki standar khusus untuk lembaga wakaf, karena legal hukum lembaga wakaf ini ialah Yayasan maka standar pelaporan mengikuti standar pelaporan untuk yayasan yaitu PSAK 45 tentang Laporan Entitas Nirlaba.

Setelah adanya PPSAK 13 tentang Pernyataan Pencabutan SAK 45 maka Standar laporan keuangan lembaga wakaf mengacu pada PSAK 112 tentang Akuntansi Wakaf (efektif 01 Januari 2021).

\section{Penyajian Laporan Keuangan Lembaga Wakaf}

Penyajian laporan keuangan entitas wakaf utamanya mengacu pada penyajian laporan keuangan nirlaba yang disesuaikan dengan karakteristik wakaf.

Laporan rincian aset wakaf adalah tambahan komponen laporan keuangan dalam PSAK 45 yang bertujuan untuk menunjukkan rincian aset wakaf yang berasal dari waqif dan hasil pengelolaan dan pengembangan aset wakaf.

1. Perubahan dari DE PSAK 112

Perubahan signifikan antara PSAK 112 yang disahkan dan Draft Eksposur PSAK 112 adalah: 
2020, Jurnal Tabarru' : Islamic Banking and Finance 3 (2) : 313 - 325

Tabel 1. Perubahan Draft Eksposur 112 Menjadi PSAK 112

Perihal

- Ruang Lingkup

PSAK 112

- Nazhir perseorangan, organisasi dan badan hukum

- Waqif organisasi dan badan hukum

Draft Eksposur PSAK 112

$\checkmark$ Nazhir Organisasi dan Badan hukum

$\checkmark$ Waqif organisasi dan Badan hukum

- Sistematika

PSAK 112

- Pendahuluan

- Entitas Pelaporan

- Pengakuan

- Penyajian

- Pengungkapan

- Kebijakan akuntansi lain

- Akuntansi Waqif

- Tanggal Efektif

- Ketentuan Transisi

Draft Eksposur PSAK 112

$\checkmark$ Pendahuluan

$\checkmark$ Akuntansi Nazhir

$\checkmark$ Akuntansi Waqif

$\checkmark$ Tanggal efektif

Ketentuan transisi

- Ketentuan transisi

PSAK 112

- Organisasi dan Badan hukum dari nazhir

- Waqif

- Entitas Wakaf

Draft Eksposur PSAK 112

$\checkmark$ Organisasi dan badan hukum nazhir Waqif

Sumber : Draft PSAK 112 


\section{Laporan Keuangan Lembaga Wakaf}

Komponen Laporan keuangan lembaga wakaf meliputi:

1. Laporan posisi keuangan,

2. Laporan rincian aset wakaf,

3. Laporan aktivitas,

4. Laporan arus kas, dan

5. Catatan atas laporan keuangan.

Berikut Tujuan, komposisi dan pelaporan untuk masing-masing laporan:

\section{Laporan Posisi Keuangan}

Tujuan laporan posisi keuangan adalah untuk memberikan informasi mengenai aset, liabilitas, aset neto dan informasi mengenai hubungan diantara unsur-unsur tersebut untuk waktu tertentu.

Informasi ini membantu para pewakaf, donatur, kreditor, dan pihakpihak lainnya untuk menilai kemampuan badan wakaf guna menjalankan amanah secara berkesinambungan, menilai likuiditas, fleksibilitas keuangan, kemampuan untuk memenuhi kewajibannya dan kebutuhan pendanaan.
Komposisi laporan keuangan terdiri dari:

a. Aset

Pada posisi aset/harta terdiri dari:

- Kas dan setara kas

- Instrumen keuangan

- Piutang

- Aset tetap dan akumulasi penyusutan

- Aset wakaf dan akumulasi penyusutan

b. Liabilitas/kewajiban terdiri dari:

- Biaya yang masih harus dibayar

- Kewajiban imbalan kerja

- Utang Lembaga

c. Aset netto/saldo aset wakaf, terdiri dari:

- Saldo wakaf tunai

- Saldo wakaf aset terikat

- Saldo wakaf aset tidak terikat

- Saldo dana pengembangan aset

\section{Contoh}

\section{Laporan Posisi Keuangan \\ Baitul Wakaf Kareema \\ Per 31 Desember 20xx}

\begin{tabular}{|c|c|c|c|}
\hline Keterangan & $\mathbf{R p}$ & Keterangan & $\mathbf{R p}$ \\
\hline ASET & & LIABILITAS & \\
\hline Aset Lancar & & $\begin{array}{l}\text { Liabilitas } \\
\text { pendek }\end{array}$ & \\
\hline Kas dan setara kas & $\mathrm{x}$ & Utang & $\mathrm{x}$ \\
\hline Piutang & $\mathrm{X}$ & $\begin{array}{l}\text { Wakaf temporer jangka } \\
\text { pendek }\end{array}$ & $\mathrm{x}$ \\
\hline Surat berharga & $\mathrm{X}$ & Liabilitas jangka pendek & $x$ \\
\hline Logam mulia & $\mathrm{x}$ & lain & $\boldsymbol{\Lambda}$ \\
\hline \multirow[t]{2}{*}{ Aset lancar lain } & $\mathrm{x}$ & & \\
\hline & & Liabilitas & \\
\hline
\end{tabular}


2020, Jurnal Tabarru' : Islamic Banking and Finance 3 (2) : 313 - 325

\begin{tabular}{|c|c|c|c|}
\hline Aset tidak lancar & & panjang & \\
\hline Surat berharga & $\begin{array}{l}x \\
x\end{array}$ & $\begin{array}{l}\text { Wakaf temporer jangka } \\
\text { panjang }\end{array}$ & $\mathrm{x}$ \\
\hline investasi pada entitas lam & $\mathrm{x}$ & $\begin{array}{l}\text { Liabilitas jangka panjang } \\
\text { lain }\end{array}$ & $\mathrm{x}$ \\
\hline Aset tak berwujud & & & \\
\hline Aset tidak lancar lain & $\begin{array}{l}x \\
x\end{array}$ & Jumlah liabilitas & $\mathrm{x}$ \\
\hline Jumlah Aset & & & \\
\hline $\begin{array}{l}\text { ASET NETO Jumlah Aset } \\
\text { Neto }\end{array}$ & & $\mathbf{x}$ & \\
\hline $\begin{array}{l}\text { Jumlah liabilitas dan aset } \\
\text { neto }\end{array}$ & & $\mathbf{x}$ & \\
\hline
\end{tabular}

Sumber: Adaptasi dan modifikasi PSAK 112

2. Laporan Rincian Aset Wakaf

Nazhir menyajikan laporan perubahan wakaf mencakup unsur berikut ini: a. Aset wakaf yang diterima waqif

b. Aset wakaf yang berasal dari hasil pengelolaan dan pengembangan.

\section{LAPORAN RINCIAN ASET WAKAF \\ Baitul Wakaf Kareema \\ Per 31 Desember 20x2 dan 20x1}

Tahun 20x2

Tahun 20x1

\begin{tabular}{lccc}
\hline \multicolumn{1}{c}{ Uraian } & Waqif & $\begin{array}{c}\text { Hasil pengelolaan dan } \\
\text { pengembangan }\end{array}$ & Jumlah \\
\hline $\begin{array}{l}\text { Kas dan setara kas } \\
\text { Piutang }\end{array}$ & $\mathrm{x}$ & $\mathrm{x}$ & $\mathrm{x}$ \\
Surat berharga: & & $\mathrm{x}$ & \\
Efek ekuitas & $\mathrm{x}$ & $\mathrm{x}$ & $\mathrm{x}$ \\
Efek utang & $\mathrm{x}$ & $\mathrm{x}$ & $\mathrm{x}$ \\
Logam mulia & $\mathrm{x}$ & $\mathrm{x}$ & $\mathrm{x}$ \\
& & & \\
Aset lancar lain: & & $\mathrm{x}$ & $\mathrm{x}$ \\
Hak sewa & $\mathrm{x}$ & $\mathrm{x}$ & $\mathrm{x}$ \\
Lainnya & $\mathrm{x}$ & $\mathrm{x}$ & $\mathrm{x}$ \\
Investasi pada entitas lain & $\mathrm{x}$ & & $\mathrm{x}$ \\
Aset tetap: & & $\mathrm{x}$ & $\mathrm{x}$ \\
Hak atas tanah & $\mathrm{x}$ & $\mathrm{x}$ & $\mathrm{x}$ \\
Bangunan & $\mathrm{x}$ & $\mathrm{x}$ & $\mathrm{x}$ \\
Hak milik satuan rumah susun & $\mathrm{x}$ & $\mathrm{x}$ & \\
Kendaraan & $\mathrm{x}$ & & \\
\hline
\end{tabular}


2020, Jurnal Tabarru' : Islamic Banking and Finance 3 (2) : 313 - 325

\begin{tabular}{llll}
\hline Tanaman & $\mathrm{x}$ & $\mathrm{x}$ & $\mathrm{x}$ \\
Lainnya & $\mathrm{x}$ & $\mathrm{x}$ & $\mathrm{x}$
\end{tabular}

Aset tak berwujud:

Hak kekayaan intelektual

Lainnya

$\begin{array}{lll}\mathrm{X} & \mathrm{X} & \mathrm{X}\end{array}$

$\mathrm{X} \quad \mathrm{X} \quad \mathrm{x}$

Aset tidak lancar lain:

$\begin{array}{llll}\text { Hak sewa } & \mathrm{x} & \mathrm{x} & \mathrm{x} \\ \text { Lainnya } & \mathrm{x} & \mathrm{x} & \mathrm{x} \\ \text { Jumlah aset } & \mathrm{x} & \mathbf{x} & \mathbf{x}\end{array}$

\begin{tabular}{lcc}
\hline Uraian & Hasil pengelolaan dan \\
pengembangan & Jumlah
\end{tabular}

$\begin{array}{llll}\text { Kas dan setara kas } & \mathrm{x} & \mathrm{x} & \mathrm{x} \\ \text { Piutang } & \mathrm{x} & \mathrm{x} & \mathrm{x} \\ \text { Surat berharga: } & - & \mathrm{x} & \mathrm{x}\end{array}$

Efek ekuitas

$\mathrm{X}-\mathrm{x}$

Efek utang

Logam mulia

$\mathrm{x}-\mathrm{x}$

$\begin{array}{lll}\mathrm{X} & \mathrm{x}\end{array}$

Aset lancar lain:

Hak sewa

$\begin{array}{lll}\mathrm{X} & \mathrm{X} & \mathrm{X}\end{array}$

Lainnya

$\mathrm{x}$

$\mathrm{x}$

Investasi pada entitas lain

Aset tetap:

Hak atas tanah $\quad x$

$\begin{array}{lll}\mathrm{x} & \mathrm{x} & \mathrm{x} \\ \mathrm{x} & \mathrm{x} & \mathrm{x} \\ \mathrm{x} & \mathrm{x} & \mathrm{x} \\ \mathrm{x} & \mathrm{x} & \mathrm{x} \\ \mathrm{X} & \mathrm{x} & \mathrm{x} \\ \mathrm{x} & \mathrm{x} & \mathrm{x}\end{array}$

Bangunan

Hak milik satuan rumah susun

Kendaraan

Tanaman

Lainnya

$\mathrm{x}$

$\mathrm{x}$

$\mathrm{X}$

$\mathrm{x}$

$\mathrm{X}$

Aset tak berwujud:

Hak kekayaan intelektual

Lainnya

$\begin{array}{lll}\mathrm{X} & \mathrm{X} & \mathrm{X}\end{array}$

$\mathrm{x} \quad \mathrm{X} \quad \mathrm{x}$

Aset tidak lancar lain:

Hak sewa

Lainnya

Jumlah aset

$\begin{array}{lll}\mathrm{X} & \mathrm{X} & \mathrm{x} \\ \mathrm{x} & \mathrm{x} & \mathrm{X} \\ \mathrm{x} & \mathrm{x} & \mathrm{X}\end{array}$

Sumber: Adaptasi dan modifikasi PSAK 112 
3. Laporan Aktivitas

Nazhir menyajikan laporan yang terdiri dari unsur:

a. Penerimaan wakaf permanen dan temporer.

b. Dampak pengukuran aset wakaf.

c. Hasil pengelolaan dan pengembangan wakaf.

d. Penyaluran wakaf.

Pada laporan ini terlihat bagaimana pengembangan dana wakaf apakah memperoleh peningkatan nilai aset atau mengalami penurunan nilai aset.

$\underline{\text { Contoh }}$

\section{LAPORAN AKTIVITAS Baitul Wakaf Kareema Periode 31 Des 20xx}

\section{PENGHASILAN}

Penerimaan wakaf permanen

Kas

$\mathrm{XXX}$

Surat Berharga

Logam mulia

Bangunan

Kendaraan

Tanaman

Hak atas tanah

Hak atas rumah susun

Hak kekayaan intelektual

Hak sewa

Lain-lain

\section{Penerimaan wakaf temporer}

Kas

Dampak pengukuran ulang aset wakaf

Kas

Surat berharga

Logam mulia

Bangunan

Kendaraan

Tanaman

Hak atas tanah

Hak milik rumah susun

Hak kekayaan intelektual

$\mathrm{XXX}$

$\mathrm{XXX}$

$\mathrm{XXX}$

$\mathrm{XXX}$

$\mathrm{XXX}$

$\mathrm{XXX}$

$\mathrm{xxx}$

$\mathrm{xxx}$

XXX
Hak sewa

XXX

Lain-lain $\quad \mathrm{xxx}$

Pengelolaan dan pengembangan aset wakaf

Bagi hasil

XXX

Dividen

$\mathrm{XXX}$

Keuntungan neto pelepasan investasi $\quad \mathrm{xxx}$

Kenaikan atau penurunan nilai invest $\mathrm{xxx}$

Beban pengelolaan dan pengembangan $\mathrm{xxx}$

Bagian nazhir atas hasil pengelolaan

dan pengembangan wakaf yang sudah

terealisasi $\mathrm{xxx}$

Jumlah $\quad \mathrm{xxx}$

Jumlah penghasilan $\quad \mathrm{xxx}$

BEBAN

Kegiatan ibadah $\quad$ xxx

Kegiatan pendidikan $\quad \mathrm{xxx}$

Kegiatan kesehatan $\quad \mathrm{xxx}$

Bantuan fakir miskin, anak terlantar, yatim piatu, beasiswa $\quad \mathrm{xxx}$

Kegiatan ekonomi umat $\quad \mathrm{xxx}$

Kegiatan kesejahteraan umum lain $\quad \mathrm{xxx}$

Jumlah beban $\quad \mathrm{Xxx}$

KENAIKAN (PENURUNAN) ASET

NETO $\quad \mathrm{xxx}$

ASET NETO AWAL PERIODE $\quad \mathrm{xxx}$ ASET NETO AKHIR PERIODE $\quad \mathrm{xxx}$

\section{Laporan Arus Kas}

Tujuan laporan arus kas menurut IAI: arus kas entitas yang berguna bagi para pengguna laporan keuangan sebagai dasar untuk menilai kemampuan entitas dalam menghasilkan kas dan setara kas serta menilai kebutuhan entitas untuk menggunakan arus kas tersebut.
Laporan arus kas (Statement of cash flow) untuk lembaga pengelola wakaf terdapat dua metode yaitu metode langsung (direct method) dan metode tidak langsung (indirect method).

\section{Contoh:}




\section{LAPORAN ARUS KAS \\ Baitul Wakaf Kareema \\ Periode ......20xx}

\section{Arus kas dari aktivitas operasi}

Kas dari waqif

$\mathrm{XXX}$

Kas dari wakaf produktif $\quad \mathrm{xxx}$

Penerimaan Lain-lain $\quad \mathrm{xxx}$

Hutang yang harus dilunasi

$\mathrm{xxx}$

$\begin{array}{cc}\text { Arus kas dari aktivitas investasi } & \\ \text { Pembelian peralatan } & \mathrm{xxx} \\ \text { Pembelian investasi } & \mathrm{xxx}\end{array}$

Arus kas dari aktivitas pendanaan

Investasi Bangunan

$\mathrm{XXX}$

\section{Kenaikan/penurunan neto investasi}

Dalam kas dan setara kas

Kas dan setara kas awal tahun $\quad \mathbf{x x x}$

Kas dan setara kas akhir tahun $\quad \mathbf{x x x}$

\section{Catatan Atas Laporan Keuangan}

Catatan atas laporan keuangan (CALK) pada organisasi/lembaga wakaf memasukkan informasi yang tidak tercantum dalam laporan posisi keuangan, laporan aktivitas, serta laporan arus kas.

\section{Implementasi PSAK 112}

Setelah menunggu sekian lama, pada tanggal 07 November 2018 DSASIAI telah mengesahkan PSAK 112: akuntansi wakaf. PSAK 112 berlaku efektif pada 01 Januari 2021 dengan opsi untuk penerapan dini. Diterbitkannya PSAK 112 ini secara umum berlandaskan pada adanya kebutuhan publik yang mendesak (public interenst theory). Sehingga pengesahan PSAK 112 menjawab tantangan atas semakin meningkatnya keinginan masyarakat atas pemberdayaan dan pengelolaan wakaf yang baik, sesuai dengan standar yang ada.

Hadirnya Standar Akuntansi Keuangan (SAK) PSAK 112: Akuntansi Wakaf, yang khusus mengatur tentang wakaf menjadi angin segar bagi perwakafan di tanah air, terutama lembaga/badan yang terlibat langsung dalam pengelolaan wakaf maupun bagi nazhir maupun waqif.

Secara umum PSAK 112 mengatur tentang perlakuan akuntansi atas transaksi wakaf yang dilakukan baik oleh nazhir maupun waqif yang berbentuk organisasi dan badan hukum. PSAK 112 ini dapat pula diterapkan oleh nazhir perorangan.

Sehingga dengan adanya Prinsip Standar Akuntansi Keuangan (SAKSyariah) PSAK 112 tentang akuntansi wakaf maka baik nazhir maupun waqif perorangan serta bagi organisasi/badan semisal Badan wakaf atau Baitul Wakaf mempunyai pedoman dalam pelaporan dana wakaf. Pengimplementasian PSAK 112 ini mempermudah pengelolaan wakaf oleh nazhir dan waqif pada Badan/lembaga wakaf baik lembaga independen maupun lembaga yang dibentuk pemerintah atau organisasi.

Sebelumnya untuk transaksi wakaf mengikuti PSAK 109 tentang Akuntansi Zakat, Infak, Sedekah, serta PSAK 45 tentang organisasi non profit/nirlaba, serta PSAK 101 tentang Penyajian Laporan Keuangan Entitas Syariah. Kehadiran PSAK 112 bagi lembaga yang terlibat dalam penghimpunan wakaf sebagai upaya peningkatan lembaga yang transparan dan akuntabel.

Adapun tujuan PSAK 112 ini adalah memberikan pengaturan mengenai pengakuan, pengukuran, penyajian, dan pengungkapan atas transaksi wakaf yang dilakukan baik oleh entitas nazhir dan waqif yang berbentuk organisasi dan badan hukum yang selama ini belum di akomodir oleh PSAK syariah yang ada, sehingga menimbulkan berbagai inkonsistensi dalam penerapannya. 


\section{KESIMPULAN}

Wakaf produktif menjadi salah satu solusi atas masalah yang dihadapi masyarakat saat ini. Selain pemberdayaan wakaf produktif yang mensejahterakan masyarakat, dibutuhkan adanya transparansi dan akuntabilitas laporan keuangan dari lembaga wakaf tersebut. Adanya aturan baku dalam hal ini tentang akuntansi zakat memudahkan pihak pengelola dalam membuat laporan keuangan berdasarkan standar. Maka dengan hadirnya PSAK 112 tentang wakaf, para pengelola dana wakaf dapat membuat laporan sesuai dengan standar tersebut dengan tata kelola yang lebih baik guna penyajian laporan keuangan yang transparan dan akuntabel.

\section{DAFTAR PUSTAKA}

Al Qaradhawi, Yusuf. 1993. Al Ibadah fi al-Islam. Muassasah Risalah.

Asnaini. 2008. Zakat, Wakaf Produktif dan Perspektif Hukum Islam. Pustaka Pelajar. Yogyakarta.

Departemen Agama RI. 2006. Alqur'an Al Tafsiruhu. Jakarta.

Departemen Agama RI. 2011. Fiqh Islam. Jakarta.

Friyanti, Yunida Een. 2017. Akuntansi Lembaga Zakat dan Wakaf. Pustaka Pelajar, IAIN Bengkulu Press.Yogyakarta.

Haniam Maria, Haniam \& Rahman, Taufikur. 2019. Analisis Penerapan Pernyataan Standar Akuntansi Keuangan (PSAK) Nomor 112 Akuntansi Wakaf Studi Kasus Pada Majelis Wakaf dan Kehartabendaan Pimpinan Wilayah Muhammadiyah DIY. Skripsi. FEB UGM. Yogyakarta.
J. Moleong, Lexy. 2007. Metode Penelitian Kualitatif. Remaja Rosdakarya. Bandung.

Nugraha, Hadias. 2019. Implementasi PSAK 112 Tentang Akuntansi Wakaf Sebelum Berlaku Efektif Pada Januari 2021. Studi Kasus pada KSU Gemi. Skripsi. UMY. Yogyakarta.

Putri, Nina Novita Sari Eka \& Santoso, Cahyo Budi. 2020. Analisa Penerapan PSAK 112 Tentang Transaksi Wakaf Terhadap Penerimaan, Pengelolaan dan Pengembangan Aset Wakaf Studi Kasus Pada Badan Wakaf Indonesia Kota Batam. Jurnal Unrika Measurement, Vol.13 No.2: 74-83. Desember 2019. Universitas Riau Kepulauan (Unrika). Batam.

Rozalinda. 2015. Manajemen Wakaf Produktif. Raja Grafindo Persada.

Sugiono. 2013. Metode Penelitian Pendidikan Pendekatan Kuantitatif, Kualitatif, dan $R \& D$. Alfabeta. Bandung. 